\title{
Age Conditional Probability of Ocular and Ocular Adnexal Malignancies
}

\author{
Mathias Nittmann ${ }^{\text {a }}$ Curtis E. Margo ${ }^{b}$ \\ ${ }^{a}$ Morsani College of Medicine, University of South Florida, Tampa, FL, USA; ${ }^{b}$ Department of Ophthalmology, \\ Pathology and Cell Biology, Morsani College of Medicine, University of South Florida, Tampa, FL, USA
}

\author{
Keywords \\ Cancer risk · Cumulative probability · Lacrimal gland \\ carcinoma - Ocular adnexal cancer - Risk assessment . \\ Uveal melanoma $\cdot$ Retinoblastoma
}

cancers, such as those found in and around the eye. The assessment of risk in terms of age-conditional probability is a versatile and an underutilized pedagogical tool.

(c) 2020 S. Karger AG, Basel

\section{Introduction}

The risk of developing cancer plays an important role in describing its epidemiology and in gaining insights into pathobiology. For ocular and ocular adnexal malignancies, the discussion of risk is confounded by the relative rarity of tumors in and around the eye. Several metrics such as mean age-adjusted incidence are usually used to communicate the risk of acquiring cancer. Age-conditional probability is one method that is conceptually accessible and takes into account the strong association of developing different types of cancer during different periods of age [1-4]. Broadly speaking, age-conditional probability can be thought of as the risk of developing a first-time cancer in a susceptible population during a specified time interval. Frequently, this estimate is expressed as a cumulative risk from birth. This type of probability calculation has been underutilized in the study of ocular and ocular adnexal malignancies in part because uncommon tumors depend upon large population-based databases.

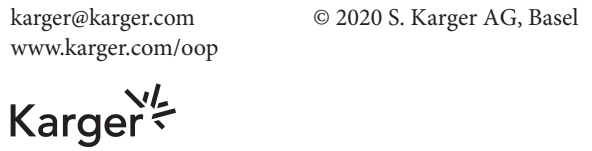


This paper describes the age-conditional probabilities of 4 ocular and ocular adnexal cancers using incidence data and vital statistics from the Surveillance, Epidemiology, and End Results (SEER) program. We discuss how age-conditional probability complements other risk metrics and its role in assessing the relative public health burden of cancer.

\section{Methods}

Datasets from SEER 18 State Registry were extracted using SEER*Stat version 8.3.6.1 [5]. All ocular and ocular adnexal malignancies except of eyelid skin from 2000 to 2017 were included in the analysis, based on the November 2019 SEER update [6]. The software and database are available from the NCI website without charge. The downloaded datasets from SEER contain incidence data for specific tumors by 5 -year age groups and gender. The denominator population for rate calculations were the susceptible populations in the 18 SEER geographic areas.

Within SEER*Stat, the Site and Morphology of Collaborative Stage Data Collection System version 02.04+ was used to extract incidence on 4 eye cancers: uveal melanoma, conjunctival melanoma, lacrimal gland carcinoma, and retinoblastoma. Uveal melanoma included iris, ciliary body, and choroid [7]. Lacrimal gland malignancies did not include lymphoma. For the overall category of "Eye and Orbit," topography codes C69.1 through 69.9 were linked to behavior code 3 for malignant neoplasm [8]. Malignancies of eyelid skin were excluded.

Incidence rates were age-adjusted to the 2000 United States (US) population $[9,10]$. Age-conditional and cumulative risks were calculated from the integral (calculus)-derived relationship of rate to probability using the life table method described by Schouten et al. [11]. Life tables for the study population were obtained from National Vital Statistics reports released annually by the Center for Disease Control (CDC) [12]. Outcomes were gender-specific and divided into 4 age groups and 5 cumulative age intervals (i.e., length of observation) for adult cancers: $0-19$ years; $20-39$ years; $40-59$ years; $60-79$ years; and lifetime. The age-interval and cumulative risks for retinoblastoma was annual through 5 years, then 5-10 years, and lifetime. Risks were expressed as single person occurrence per susceptible population with proportional rounding to 3 places. As a means of confirming the general validity of our analyses, we examined the lifetime risks of 3 common cancers (lung-bronchus, breast, and prostate) for comparison with previously published cumulative risks from SEER $[13,14]$.

\section{Results}

Age-interval and cumulative probabilities of uveal and conjunctival melanoma are shown in Table 1, and lacrimal gland carcinoma and all ocular and ocular adnexal cancers in Table 2. Women throughout life are less likely to have these 3 malignancies or cumulative ocular/ocular adnexal cancer overall compared to men. Uveal melano- ma was the most common malignancy among them, having a lifetime probability of 1 in 1,720 and 1 in 1,980 in men and women, respectively. The lifetime risk of cancer of the lacrimal gland was 1 in 45,600 for men and 1 in 63,900 for women. Conjunctival melanoma fell between these extremes. By comparison, the lifetime risk of uveal melanoma in men is roughly 200 times less than developing prostate cancer and in women nearly 250 times less than developing breast cancer (Tables 1, 3).

Table 4 displays the annual interval and cumulative risk of retinoblastoma to age 5 , risk between 5 and 10 years of age, and lifetime risk. The differences in gender risk at these age intervals were small enough to warrant combining genders. As Table 4 illustrates, there was a considerable decline in risk of retinoblastoma after age 3 , and negligible lifetime risk after age 5. During the first year of life, the probability of retinoblastoma is 1 in 34,800 .

Our calculations for lifetime risk of carcinoma of the lung-bronchus, breast, and prostate compared favorably to 2 previous SEER studies (Table 3) $[13,14]$.

\section{Discussion}

Ocular and ocular adnexal cancers are uncommon to rare, but verbal descriptors of occurrence are subjective and prone to differing interpretations by both lay persons and medical professionals [15]. A common surrogate for communicating risk is incidence, or the probability of developing cancer over a stated period of time. Cancer incidence can be reported in various ways from average age adjusted to age stratified [16]. Given the strong age-dependent profile of all cancers, age-conditional probability is a valuable method of communicating risk as it applies to specific clinical situations. The validity of the estimate, however, depends on accurate counts of new cancer cases and approximation of the denominator population at risk as it changes over time intervals. For this reason, we relied upon the SEER database for cross-sectional incidence and the CDC for vital statistics.

Our finding that men are at greater risk of the 3 adult cancers examined in this study compared to women is consistent with the overall heightened susceptibility of men to many common malignancies [17]. Analysis of the SEER 2004-2008 database, age-adjusted to the 2000 US standard population, had shown the incidence rate for all cancers for men was 553 per 100,000 compared to 416.4 for women [18]. Similarly, the lifetime risk of developing cancer was $44.8 \%$ for men compared to $38.1 \%$ for women [18]. The reasons are likely multifactorial, probably often

Age Conditional Probability of Ocular 
Table 1. Age interval and cumulative risks of uveal and conjunctival melanoma by gender

\begin{tabular}{|c|c|c|c|c|c|c|c|c|}
\hline \multirow{3}{*}{$\begin{array}{l}\text { Age } \\
\text { interval, } \\
\text { years }\end{array}$} & \multicolumn{4}{|c|}{ Uveal melanoma } & \multicolumn{4}{|c|}{ Conjunctival melanoma } \\
\hline & \multicolumn{2}{|l|}{ male } & \multicolumn{2}{|l|}{ female } & \multicolumn{2}{|l|}{ male } & \multicolumn{2}{|l|}{ female } \\
\hline & $\begin{array}{l}\text { interval } \\
1 \text { in: }\end{array}$ & $\begin{array}{l}\text { cumulative } \\
1 \text { in: }\end{array}$ & $\begin{array}{l}\text { interval } \\
1 \text { in: }\end{array}$ & $\begin{array}{l}\text { cumulative } \\
1 \text { in: }\end{array}$ & $\begin{array}{l}\text { interval } \\
1 \text { in: }\end{array}$ & $\begin{array}{l}\text { cumulative } \\
1 \text { in: }\end{array}$ & $\begin{array}{l}\text { interval } \\
1 \text { in: }\end{array}$ & $\begin{array}{l}\text { cumulative } \\
1 \text { in: }\end{array}$ \\
\hline $0-19$ & 588,000 & 588,000 & 460,000 & 460,000 & $1,580,000$ & $1,580,000$ & $1,320,000$ & $1,320,000$ \\
\hline $20-39$ & 39,600 & 37,600 & 39,200 & 36,400 & 367,000 & 301,000 & 546,000 & 276,000 \\
\hline $40-59$ & 6,640 & 5,860 & 7,970 & 6,660 & 129,000 & 93,100 & 153,000 & 99,800 \\
\hline $60-79$ & 2,730 & 2,070 & 3,410 & 2,390 & 38,700 & 30,500 & 50,200 & 35,500 \\
\hline Lifetime & & 1,720 & & 1,980 & & 20,900 & & 25,600 \\
\hline
\end{tabular}

Table 2. Age interval and cumulative risks of lacrimal gland carcinoma and all ocular adnexal malignancies

\begin{tabular}{|c|c|c|c|c|c|c|c|c|}
\hline \multirow{3}{*}{$\begin{array}{l}\text { Age } \\
\text { interval, } \\
\text { years }\end{array}$} & \multicolumn{4}{|c|}{ Lacrimal gland carcinoma } & \multicolumn{4}{|c|}{ All ocular and ocular adnexal malignancies* } \\
\hline & \multicolumn{2}{|l|}{ male } & \multicolumn{2}{|l|}{ female } & \multicolumn{2}{|l|}{ male } & \multicolumn{2}{|l|}{ female } \\
\hline & $\begin{array}{l}\text { interval } \\
1 \text { in: }\end{array}$ & $\begin{array}{l}\text { cumulative } \\
1 \text { in: }\end{array}$ & $\begin{array}{l}\text { interval } \\
1 \text { in: }\end{array}$ & $\begin{array}{l}\text { cumulative } \\
1 \text { in: }\end{array}$ & $\begin{array}{l}\text { interval } \\
1 \text { in: }\end{array}$ & $\begin{array}{l}\text { cumulative } \\
1 \mathrm{in:}\end{array}$ & $\begin{array}{l}\text { interval } \\
1 \text { in: }\end{array}$ & $\begin{array}{l}\text { cumulative } \\
1 \text { in: }\end{array}$ \\
\hline $0-19$ & $3,670,000$ & $3,670,000$ & $2,600,000$ & $2,600,000$ & 12,300 & 12,300 & 12,700 & 12,700 \\
\hline $20-39$ & 367,000 & 484,000 & 669,000 & 536,000 & 25,000 & 8,320 & 27,800 & 8,730 \\
\hline $40-59$ & 152,000 & 120,000 & 288,00 & 190,268 & 4,890 & 3,170 & 6,340 & 3,720 \\
\hline $60-79$ & 77,100 & 51,400 & 119,000 & 77,283 & 1,800 & 1,270 & 2,640 & 1,630 \\
\hline Lifetime & & 45,600 & & 63,900 & & 1,020 & & 1,330 \\
\hline
\end{tabular}

* Includes all intraocular and ocular adnexal/orbital malignancies except eyelid skin. See Methods for corresponding ICD-O codes.

Table 3. Lifetime risk of developing common cancers (2017)

\begin{tabular}{|c|c|c|c|}
\hline \multirow[t]{2}{*}{ Tumor } & \multirow{2}{*}{$\begin{array}{l}\text { Current } \\
\text { study } \\
\text { lifetime risk } \\
2000-2017 \\
\text { USA } 1 \text { in: }\end{array}$} & \multicolumn{2}{|c|}{$\begin{array}{l}\text { Published lifetime risk } 1 \\
\text { in: }\end{array}$} \\
\hline & & $\begin{array}{l}\text { 1991-2016 } \\
\text { USA* }^{*}\end{array}$ & $\begin{array}{l}\text { 1998-2000 } \\
\text { USA }^{\dagger}\end{array}$ \\
\hline Lung and bronchus (overall) & 15.4 & - & - \\
\hline Men & 14.7 & 15 & 13 \\
\hline Women & 17.1 & 17 & 17 \\
\hline Prostate (men) & 7.3 & 9.0 & 6.0 \\
\hline Breast (women) & 8.2 & 8.0 & 7.0 \\
\hline
\end{tabular}

* SEER data from Siegel et al. [13]. ${ }^{\dagger}$ SEER data from Gloeckler Ries et al. [14].

tumor specific, include genetic and environmental influences, and remain largely speculative and the focus of investigation [17].

Our results support the generally acknowledged low probability of developing an ocular or ocular adnexal cancer. Although none of the results are unexpected, the
Table 4. Retinoblastoma age interval and cumulative risks

\begin{tabular}{lll}
\hline $\begin{array}{l}\text { Age interval, } \\
\text { years }\end{array}$ & \multicolumn{2}{l}{ Retinoblastoma* } \\
\cline { 2 - 3 } & age-interval risk 1 in: & cumulative risk 1 in: \\
\hline $0-1$ & 34,800 & 34,800 \\
$1-2$ & 60,500 & 22,100 \\
$2-3$ & 74,900 & 17,100 \\
$3-4$ & 226,000 & 15,900 \\
$4-5$ & 421,000 & 15,300 \\
$5-10$ & 462,000 & 14,700 \\
\hline Lifetime & & 14,600
\end{tabular}

* Gender risks not different at this level of rounding.

display of information is edifying. Even for the most frequently studied ocular malignancy uveal melanoma, ageconditional risks complement what is known about its epidemiology [19-21]. Examining specific cancers using age interval and cumulative probabilities are not new. SEER has been reporting them for many common cancers 
since the 1990s, but to our knowledge, ocular and ocular adnexal malignancies have not been described in this manner. Age-conditional cancer risk is a useful means of exploring the public health burden of cancers as it permits comparison across cancer types and age groups [3]. It also poses cancer risk in a format that is easy to assimilate and potentially instructive.

\section{Conclusions}

Age interval and cumulative probabilities of ocular and ocular adnexal cancer can be calculated using crosssectional incidence and population vital statistics from sources such as SEER $[13,14]$. Age-conditional probabilities can be examined at various age intervals and according to various patient characteristics (e.g., gender, race, ethnicity, etc.), iterations of which are limited by the interests of investigators and availability of collected data. Age-conditional risk is conceptually friendly and can be used as a pedagogical tool.

\section{Statement of Ethics}

This study complied with guidelines of human research as it applies to protected health information in medical records. The study was exempted by the Institutional Review Board of the Morsani College of Medicine as the data used in analyses was collective, devoid of personal identifiers, and existed in public domain.

\section{Conflict of Interest Statement}

The authors have no ethical, proprietary, or commercial conflicts of interest.

\section{Funding Sources}

There are no funding sources to declare.

\section{Author Contributions}

C.E.M. concept/application; M.N. data collection; M.N. and C.E.M. data analysis; C.E.M. original draft of the manuscript; M.N. and C.E.M. revision of the manuscript; M.N. and C.E.M. creation of the tables.

\section{References}

1 Wun LM, Merrill RM, Feuer EJ. Estimating lifetime and age-conditional probabilities of developing cancer. Lifetime Data Anal. 1998; 4(2):169-86.

2 Fay MP, Pfeiffer R, Cronin KA, Le C, Feuer EJ. Age-conditional probabilities of developing cancer. Stat Med. 2003 Jun;22(11):1837-48.

3 Merrill RM, Weed DL. Measuring the public health burden of cancer in the United States through lifetime and age-conditional risk estimates. Ann Epidemiol. 2001 Nov;11(8): $547-53$.

4 Sasieni PD, Shelton J, Ormiston-Smith N, Thomson CS, Silcocks PB. What is the lifetime risk of developing cancer?: the effect of adjusting for multiple primaries. Br J Cancer. 2011 Jul;105(3):460-5.

5 Surveillance Research Program, National Cancer Institute SEER*Stat software (www. seer.cancer.gov/seerstat) version 8.3.6.1. (last accessed: July 19, 2020).

6 Surveillance E, Results E. (SEER) Program (www.seer.cancer.gov) SEER*Stat Database: Incidence - SEER Research Data, 18 Registries, Nov 2019 Sub (2000-2017) - Linked To County Attributes - Time Dependent (19902017) Income/Rurality, 1969-2018 Counties, National Cancer Institute, DCCPS, Surveillance Research Program, released April 2020, based on the November 2019 submission (last accessed: July 19, 2020).
7 AJCC Cancer Staging Manual (7th ed). Edge SB, Byrd DR, Compton CC, Fritz AG, Greene FL, Trotti A (eds). New York: Springer; 2010.

8 International Classification of Diseases for Oncology. Percy C, Holten VV, Muir C (eds), 2nd Edition. World Health Organization: Geneva; 1996.

9 Klein RJ, Schoenborn CA. Age Adjustment Using the 2000 Projected U.S. Population. Healthy People 2010 statistical notes: no. 20. Hyattsville, Maryland: National Center for Health Statistics. 2001. Available from: https://ibis.health.utah.gov/ibisph-view/pdf/ resource/query/statnt20.pdf (accessed online: May 20, 2020).

10 Anderson RN, Rosenberg HM. Age Standardization of Death Rates: Implementation of the Year 2000 Standard. National vital statistics reports: vol 47 no. 3. Hyattsville, Maryland: National Center for Health Statistics; 1998.

11 Schouten LJ, Straatman H, Kiemeney LA, Verbeek AL. Cancer incidence: life table risk versus cumulative risk. J Epidemiol Community Health. 1994 Dec;48(6):596-600.

12 Centers for Disease Control and Prevention. National Vital Statistics Reports: United States Life Tables. Available from: https:// www.cdc.gov/nchs/data/nvsr/nvsr47/ nvs47_03.pdf (accessed online: May 20, 2020).

13 Siegel RL, Miller KD, Jemal A. Cancer statistics, 2019. CA Cancer J Clin. 2019 Jan;69(1): $7-34$.
14 Gloeckler Ries LA, Reichman ME, Lewis DR, Hankey BF, Edwards BK. Cancer survival and incidence from the Surveillance, Epidemiology, and End Results (SEER) program. Oncologist. 2003;8(6):541-52.

15 Büchter RB, Fechtelpeter D, Knelangen M, Ehrlich M, Waltering A. Words or numbers? Communicating risk of adverse effects in written consumer health information: a systematic review and meta-analysis. BMC Med Inform Decis Mak. 2014 Aug;14(1):76.

16 Kelsey JL, Thompson WD, Evans AS. Methods in Observational Epidemiology. New York: Oxford University Press; 1986.

17 Dorak MT, Karpuzoglu E. Gender differences in cancer susceptibility: an inadequately addressed issue. Front Genet. 2012 Nov;3:268.

18 Siegel R, Naishadham D, Jemal A. Cancer statistics, 2012. CA Cancer J Clin. 2012 Jan-Feb; 62(1):10-29.

19 Andreoli MT, Mieler WF, Leiderman YI. Epidemiological trends in uveal melanoma. Br J Ophthalmol. 2015 Nov;99(11):1550-3.

20 Singh AD, Turell ME, Topham AK. Uveal melanoma: trends in incidence, treatment, and survival. Ophthalmology. 2011 Sep; 118(9):1881-5.

21 Aronow ME, Topham AK, Singh AD. Uveal Melanoma: 5-year update on incidence, treatment, and survival (SEER 1973-2013). Ocul Oncol Pathol. 2018 Apr;4(3):145-51.
Age Conditional Probability of Ocular and Ocular Adnexal Malignancies
Ocul Oncol Pathol 2021;7:70-73 DOI: $10.1159 / 000511364$ 